\title{
At-4/1, an Interactor of the Tomato spotted wilt virus Movement Protein, Belongs to a New Family of Plant Proteins Capable of Directed Intra- and Intercellular Trafficking
}

\author{
Martina Paape, ${ }^{1}$ Andrey G. Solovyev, ${ }^{2}$ Tatyana N. Erokhina, ${ }^{3}$ Elena A. Minina, ${ }^{3}$ \\ Mikhail V. Schepetilnikov, ${ }^{2}$ Dietrich-E. Lesemann, ${ }^{4}$ Joachim Schiemann, ${ }^{4}$ \\ Sergey Yu. Morozov, ${ }^{2}$ and Jan-W. Kellmann ${ }^{1}$ \\ ${ }^{1}$ University of Rostock, Biology Institute, Albert Einstein Str. 3, 18059 Rostock, Germany; ${ }^{2}$ A. N. Belozersky Institute of \\ Physico-Chemical Biology, Moscow State University, Moscow 119899, Russia; ${ }^{3}$ M. M. Shemyakin \& Yu. A. Ovchinnikov \\ Institute of Bioorganic Chemistry, Russian Academy of Sciences, 16/10 Miklukho-Maklaya Str., 117997 Moscow, Russia; \\ ${ }^{4}$ Institute of Plant Virology, Microbiology and Biosafety, Federal Biological Research Centre for Agriculture and Forestry, \\ Messeweg 11/12, 38104 Braunschweig, Germany
}

Submitted 11 November 2005. Accepted 23 March 2006.

\begin{abstract}
The Tomato spotted wilt virus (TSWV) encoded NSm movement protein facilitates cell-to-cell spread of the viral genome through structurally modified plasmodesmata. NSm has been utilized as bait in yeast two-hybrid interaction trap screenings. As a result, a protein of unknown function, called At-4/1, was isolated from an Arabidopsis thaliana GAL4 activation domain-tagged cDNA library. Using polyclonal antibodies against bacterially expressed At-4/1, Western blot analysis of protein extracts isolated from different plant species as well as genome database screenings showed that homologues of At-4/1 seemed to be encoded by many vascular plants. For subcellular localization studies, At-4/1 was fused to green fluorescent protein, and corresponding expression vectors were used in particle bombardment and agroinfiltration assays. Confocal laser scannings revealed that At-4/1 assembled in punctate spots at the cell periphery. The protein accumulated intracellularly in a polarized fashion, appearing in only one-half of a bombarded epidermal cell, and, moreover, moved from cell to cell, forming twin-structured bodies seemingly located at both orifices of the plasmodesmatal pore. In coexpression studies, At-4/1 colocalized with a plant virus movement protein TGBp3 known to reside in endoplasmic reticulumderived membrane structures located in close vicinity to plasmodesmata. Thus, At-4/1 belongs to a new family of plant proteins capable of directed intra- and intercellular trafficking.
\end{abstract}

Additional keywords: cell-to-cell trafficking.

It generally is accepted that plant-infecting viruses utilize plasmodesmata (PD) and endogenous transport machineries to transfer their genomes throughout the plant (Heinlein and Epel 2004; Lazarowitz and Beachy 1999; Lucas 2006; Oparka

Corresponding author: J.-W. Kellmann; Telephone: +49 364157 1000; Fax: +49 364157 1002; E-mail: jkellmann@ice.mpg.de

Current address of Jan-W. Kellmann: Max Planck Institute for Chemical Ecology, Hans Knoell Str. 8, 07745 Jena, Germany.
2004; Scholthof 2005; Tzfira et al. 2000; Waigmann et al. 2004). In higher plants, PD represent plasma membrane-lined, cell-wall-crossing cytoplasmic channels containing an appressed tubule derived from endoplasmic reticulum (ER). The cytoplasm, the plasma membrane, and the ER of neighboring cells are a continuous network, forming a syncytium throughout the plant body (Heinlein and Epel 2004). Due to the technical difficulties of isolating PD from the cell wall fraction of plant tissues, only few proteins localized to PD have been identified so far. These include a myosin-like protein, an unconventional myosin VIII, actin-related proteins, centrin, calreticulin, a homologue of GTPase Rab11, and several other proteins with unknown functions (Lucas and Lee 2004; Oparka 2004; Heinlein and Epel 2004).

Plant-virus encoded movement proteins (MPs) were the first proteins identified as capable of cell-to-cell movement. MPs are able to increase the size exclusion limit of PD and move from cell to cell in plant tissue, hence representing a feasible tool to determine structure and function of PDs (Haywood et al. 2002; Heinlein and Epel 2004; Lucas 2006; Waigmann et al. 2004). MPs exhibit nucleic-acid-binding properties, and many plant-virus genomes are transported to PD as ribonucleoprotein complexes containing MPs. However, it remains unclear whether undissociated RNP are able to be transported through PD pores (Citovsky et al. 1992; Kiselyova et al. 2001; Kragler et al. 1998; Nelson 2005; Scholthof 2005; Tzfira et al. 2000; Waigmann et al. 2004).

MPs encoded by different genera of plant viruses can be divided into several groups (Heinlein and Epel 2004; Lucas 2006; Melcher 2000; Morozov and Solovyev 1999; Nelson 2005). Importantly, even divergent MPs may share key structural elements. Nevertheless, the number of MPs substantially varies in the different viral taxonomic groups (Morozov and Solovyev 2003; Scholthof 2005). In many cases, viral genomes encode one single MP, and one of the best-studied MPs of this specimen is the Tobacco mosaic virus (TMV) 30-kDa protein (Carrington et al. 1996; Heinlein and Epel 2004; Lucas 2006; Nelson 2005; Waigmann et al. 2004). Three MPs to facilitate cell-to-cell and very likely vascular movement are required by a number of virus genera with positive-stranded RNA genomes, and their partially overlapping genes encoding these MPs con- 
stitute the so-called triple gene block (TGB) (Lucas 2006; Morozov and Solovyev 2003; Verchot-Lubicz 2005).

It long has been recognized that data on functional interactions between MPs and host proteins are crucial for understanding potential mechanisms of virus cell-to-cell trafficking. A number of cell proteins that interact specifically with MPs have been identified, mainly by using yeast two-hybrid interaction trap and far-western assays (Chen et al. 2005; Heinlein 2002; Kellmann 2001; Oparka 2004; Scholthof 2005; Waigmann et al. 2004).

Using the Tomato spotted wilt virus (TSWV)-encoded MP (termed NSm, a nonstructural protein) as bait in yeast twohybrid assays, von Bargen and associates (2001) identified an interacting protein which is called At-4/1, and the corresponding cDNA was isolated from an Arabidopsis thaliana GAL4 activation domain-tagged library. In this article, we present studies on the subcellular localization of At-4/1 and report on structural predictions and sequence comparison data. Together, these results suggest that At-4/1-like proteins represent a new family of plant proteins which potentially are involved in intercellular communication through PD.

\section{RESULTS}

\section{Presence of At-4/1-related coding sequences in plant genomes.}

Cloning of a partial cDNA isolated from an A. thaliana cDNA library utilizing yeast two-hybrid assays with the TSWV MP as bait, termed A. thaliana 4/1 (GenBank accession number AY212284), previously has been reported by von Bargen and associates (2001). The originally isolated cDNA derived from the At-4/1 gene bears the nearly complete coding region (except 15 nucleotides encoding five $\mathrm{N}$-terminal amino acids) and the entire stretch of 236 nucleotides of the $3^{\prime}$ untranslated region. The corresponding single copy gene (GenBank accession number NC_003075; locus At4g26020.1) is localized on chromosome IV and includes eight coding exons and seven introns, resulting in a putative mRNA encoding a polypeptide of 247 amino acids (accession number NP_194332.2) with a predicted molecular mass of $29.1 \mathrm{kDa}$. Our $\overline{5}$ ' rapid amplification of cDNA ends (RACE) experiments identified the exact borders for the At-4/1 open reading frame. It was found that the $5^{\prime}$ untranslated region (UTR) of At- $4 / 1 \mathrm{mRNA}$ is 75 nucleotides long (data not shown). The 5' UTR does not contain AUG codons. Thus, we conclude that the translational start of At-4/1 predicted on the basis of the genomic sequence corresponds to the actual initiator codon.

Different databases (including expressed sequence tags [EST] and genomic survey DNA sequences) available in the National Center for Biotechnology Information (NCBI) were screened for At-4/1-like sequences using BLASTP and TBLASTN programs (Fig. 1). Full-length At-4/1-related coding sequences were found among annotated cDNA sequences from rice (Oryza sativa var. japonica) and in EST database sequences from Aquilegia formosa $\times$ pubescens, sugarcane (Saccharum officinarum), and barley (Hordeum vulgare); in the latter, nearly the complete coding region aligned to At-4/1. Additional full-length 4/1-like coding sequences from Lactuca sativa, Zea mays, Medicago truncatula and Populus balsamifera could be reconstructed by comparing the At-4/1 gene sequence with the corresponding genome survey sequences available in the NCBI.

Secondary structure comparisons of $4 / 1$ proteins revealed that these proteins display extended coiled-coil domains, as estimated using the COILS algorithm (Lupas 1996; Lupas et al. 1991). In addition, $4 / 1$ proteins show some similarities to myosin-, kinesin-, and ankyrin-like proteins, as already discussed by von Bargen and associates (2001).
Immunodetection of At-4/1-related proteins in different plant species.

Polyclonal antibodies against a deletion mutant of At-4/1 lacking the most variable $\mathrm{N}$-terminal region (positioned in front of the first leucine zipper region) (Fig. 1) were raised in rabbits and mice. Sequence comparisons led us to expect that antibodies against the most conserved area of 4/1 protein would efficiently recognize 4/1-like proteins of different origin and, hence, be suitable for detecting the proteins in different plant species.

Leaves of Nicotiana benthamiana, N. tabacum, Datura stramonium, O. sativa, and A. thaliana were harvested and analyzed by Western blotting using At-4/1-specific antibodies. Polyclonal antibodies were found to detect a single protein band in leaves of $A$. thaliana corresponding to the predicted size of approximately $29 \mathrm{kDa}$. Moreover, we determined single protein bands of approximately the same molecular weight in other dicots and monocots (Fig. 2).

\section{Subcellular localization of At-4/1-green fluorescent fusion protein: Peripheral punctae and polar distribution in leaf epidermal cells.}

Transient expression assays following particle bombardment were performed with $A$. thaliana and $N$. benthamiana leaves to study subcellular localization of At- $4 / 1$ fused to the green fluorescent protein (GFP) fluorescent marker (Brandizzi et al. 2002a). Both N- and C-terminal GFP fusions of At-4/1 protein were expressed under the control of the Cauliflower mosaic virus (CaMV) 35S promoter. Confocal laser scanning microscopy (CLSM) was performed approximately $20 \mathrm{~h}$ after particle bombardment. Observations of the fluorescent proteins in leaf epidermal cells of $A$. thaliana and $N$. benthamiana are shown in Figure 3. The N-terminal GFP-At-4/1 fusion was observed in the cytosol and the nuclei (Fig. 3B), similar to the localization of nonfused GFP (Fig. 3A). In contrast, the C-terminal fusion At-4/1-GFP accumulated in both plant species as peripheral punctae at the cellular periphery (Fig. 3C to G). A striking feature of At-4/1-GFP was a polarized distribution of peripheral fluorescent punctae in epidermal cells of $A$. thaliana and $N$. benthamiana leaves. The protein was localized predominantly in one-half of an epidermal cell (Fig. 3G). This localization pattern was found in multiple independent bombardment experiments, with some variation in the relative abundance of fluorescent structures on opposite sides of the cell.

At a preliminary stage of our work, we constructed identical deletion mutants for the N-terminal and C-terminal GFP fusions of At-4/1. Using C-terminal fusions, we found that several mutant proteins localized diffusely, in contrast to the punctate and polarized phenotype of the C-terminal fusion of the wild-type At- $4 / 1$ protein. On the other hand, all mutants of the N-terminal fusion showed the same diffused localization as the wild-type protein. Later, we determined a point mutation in At-4/1 that changed the punctate and polarized localization of the C-terminal fusion into a diffused phenotype (unpublished data). These data indicate that i) the ER-localized punctae observed for the C-terminal fusion are not an artifact of overexpression and ii) only the $\mathrm{C}$-terminal fusion is able to compartmentalize in living cells. This also was confirmed by the polarized localization of this fusion in epidermal and other leaf cells, such as guard and trichome cells (unpublished data).

A characteristic feature of the At-4/1-GFP punctae was their bright fluorescence even at low-laser-light exposures, suggesting large amounts of the protein at potential cellular targets. In single optical sections traversing the middle of the epidermal cell layer, GFP fluorescence was found in peripheral punctae (Fig. 3D). These At-4/1-GFP structures were phenotypically 
similar to the peripheral bodies found in our previous studies within cells expressing the viral TGBp3 MP of Poa semilatent virus (PSLV, genus Hordeivirus) (Solovyev et al. 2000; Zamyatnin et al. 2002). At-4/1-GFP-containing bodies also were visible on the upper and lower cell surfaces (Fig. 3E), which resembled the transient expression data obtained with the TGBp3 MP (Solovyev et al. 2000).

Because the TGBp3-containing peripheral bodies previously were proposed to represent membrane structures originating in the ER (Gorshkova et al. 2003; Schepetilnikov et al. 2005), $N$. benthamiana leaves were cobombarded with two expression vectors coding for At-4/1-GFP and ER-yellow fluorescent protein (YFP). The latter plasmid carried the gene of ER-targeted YFP (Zamyatnin et al. 2004). In cobombarded cells, as ex-

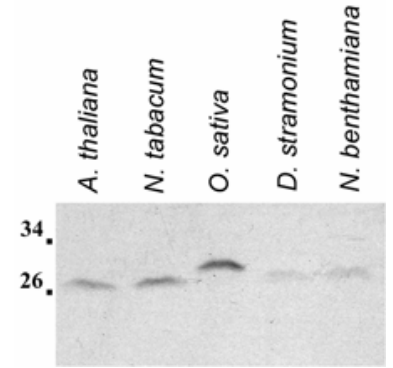

Fig. 2. Immunodetection of At-4/1 and immunologically related proteins in a number of plant species which are covered by sequence data. Proteins were detected with antibodies against the Arabidopsis thaliana At-4/1 protein. Positions of molecular mass markers $(\mathrm{kDa})$ are indicated in the left.

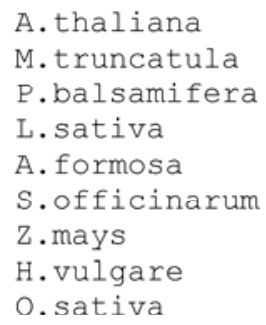

\begin{abstract}
KLYTESLNNFADQLEHRTKCHSLKEELKRVNDENKSKEHEHRNALESLRQKHVTKVEELEYKIR KLYSESLKNVADQLDFRAKYMNLKEELERSNNEVVSKE SGHRRALKLLEEEYNEKIARLEAQVK KLYTGSLNNLAEELERRTKCVSLNEE LKRLRDELINNEDEHKKAVELLKKDYTTKVGELEDQIR KLYTES INKLASQLECRNNCRSLKEELKRVNDEYIRKENELRNAMSLLKHDYEKRIKELEIQIK KLYTDSLNRLSNQIERRSKCQSLKEELKKLNDEQFIKEEEHKKAVDLLKRE YAAAIEDLETQVR RLYTETLFKFTNQVKFHAEAQSLKEELEKANSRLLSMEEEHKRETEQLKHSSEMNINALENKLS RQYTETLFKVTNQVKFRAEAQSLKEELDKANSRLLSMEEEHKRETEQLKHSSEMNINALENKLS RLYTETLFKFTNQMKYHTEAQSLKEELGKANSRLVSMEEEHKRE IEQLKHDNEMNCNALENKLS RLYTETLFKFTNQMKFHTE SRNLKEELEKANTRLLSMEEEYKRE IEQLKLGSEMNSNDLENKLS
\end{abstract}

\author{
A. thaliana \\ M.truncatula \\ P.balsamifera \\ L. sativa \\ A. formosa \\ S.officinarum \\ Z.mays \\ H. vulgare \\ O.sativa
}

SLLVEKATNDMVIDRLRQDLTANKSH IQAMSKKLDRVVTEVECKYELE IQDLKDCLLMEQAEKN ESLHEKASYEATI SQLHGD IAAHKNHMQILANRLDQVHFEVESKYSSE IRDLKDCLMAEQEEKN GFLLGKETNEATVTHLRQDIAAHKAHMQTLANRLDRVAFEVESKYHLELQDLKDCLMIEQEEKN DSIVQKTANESTINQLHQDLGAHRNHVEASSKRSRRVHSDAEMTYQTEI $\times$ XXXXXXX CFLLQQAEKEE TINQLRADLATHKKHIEALSRRLERVHDDIESKHHHEVQDLKDWLLVEQEEKY HAFVQQASGEAAMKQLKLELSAHKSHIDMLGSRLEQVTADVHSQYKNE IQDLRDVISVEQEEKK HALVQQARDEAAMKQLKLEL SAHKSHIDMLGSRLEQVTNDVHSQYKNE IQDLRDVVSVEQEEKK CAFVQQAADKAS IKQLKLDLGAHKAHIDMLGSKLEQVTAEAHMKYKNDIQDLHDVIMVEQEEKD CAVVQQATNEAVIKQLNLELEAHKAHIDMLNSRLEQVTADVHQQYKNEIQDLKDVVIVEQEEKN
A. thaliana
M.truncatula
P.balsamifera
A. formosa
S.officinarum
Z.mays
H. vulgare
o. sativa

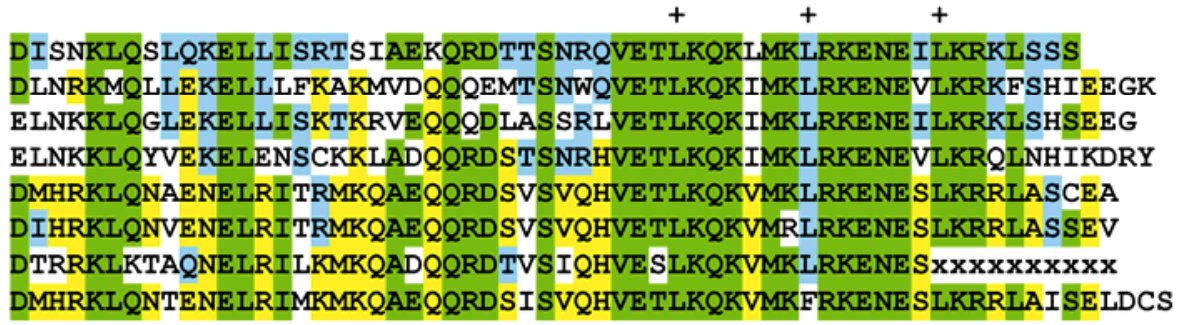

DISNKLQSLQKELLISRTSIAEKQRDTTSNRQVETLKQKLMKLRKENE ILKRKLSSS DLNRKMQLLEKELLLFKAKMVDQQQEMTSNWQVETLKQKIMKLRKENEVLKRKFSHIEEGK ELNKKLQGLEKELLISKTKRVEQQQDLASSRLVETLKQKIMKLRKENE ILKRKLSHSEEG ELNKKLQYVEKELENSCKKLADQQRDSTSNRHVETLKQKIMKLRKENEVLKRQLNHIKDRY DMHRKLQNAENELRITRMKQAEQQRD SVSVQHVETLKQKVMKLRKENE SLKRRLASCEA DIHRKLQNVENELRITRMKQAE $Q Q R D$ SVSVQHVE TLKOKVMRLRKENE SLKRRLASSEV
DTRRKLKTAONELRILKMKOADOORDTVSIOHVE SLKOKVMKLRKENE S $\mathbf{x} \mathbf{x} \mathbf{x} \mathbf{x} \mathbf{x} \mathbf{x} \mathbf{x} \mathbf{x} \mathbf{x}$ DMHRKLQNTENELRIMKMKQAEQQRDS ISVQHVETLKQKVMKFRKENE SLKRRLAISELDCS

Fig. 1. Multiple amino acid sequence alignment of 4/1-like proteins. The amino acid-residues conserved in both Arabidopsis thaliana and Oryza sativa sequences are shaded in green. Residues conserved solely in $A$. thaliana are shown in blue. Residues conserved solely in $O$. sativa are shown in yellow. The conserved hydrophobic residues forming heptads (potential leucine zippers) in 4/1-like proteins are shown by (+) above the At-4/1 sequence. Nonsequenced regions are shown by (x). Amino acid sequence identity between $A$. thaliana and $O$. sativa is $42 \%(36 \%$ in the $\mathrm{N}$-terminal area corresponding to the sequenced part of Lactuca sativa $4 / 1$-like protein). L. sativa vs. A. thaliana $=48 \%$, vs. O. sativa $=35 \%$. Medicago truncatula vs. A. thaliana $=54 \%(50 \%)$, vs. O. sativa $=$ $41 \%(37 \%)$. Populus balsamifera vs. A. thaliana $=60 \%(55 \%)$, vs. O. sativa $=42 \%(34 \%)$. Aquilegia formosa $\times$ pubescens vs. A. thaliana $=52 \%(48 \%)$, vs. O. sativa $=44 \%(40 \%)$. Saccharum officinarum vs. A. thaliana $=42 \%(35 \%)$, vs. O. sativa $=80 \%(76 \%)$. Zea mays vs. A. thaliana $=42 \%(30 \%)$, vs. O. sativa $=76 \%(66 \%)$. Hordeum vulgare vs. A. thaliana $=40 \%(35 \%)$, vs. O. sativa $=76 \%(75 \%)$. 
pected, GFP fluorescence was detected mostly in punctae at the cellular periphery (Fig. 3I and L). However, based on subcellular fluorescent patterns, we conclude that ER-YFP displayed two phenotypes. In approximately $15 \%$ of the cells, ER-YFP was found in both the typical ER network and the peripheral bodies, suggesting that expression of At-4/1-GFP did not significantly affect the ER (Fig. 3I to K). Nevertheless, in most cases, overexpression of At-4/1-GFP resulted in the reorganization of the ER into large condensed structures (Fig. 3L to N). Importantly, in the cells of both phenotypes, the presence of the ER marker in the At-4/1-containing peripheral punctae demonstrated that they represented putative membrane structures that originated in the ER.

\section{Cell-to-cell movement of At-4/1-GFP fusion.}

Examination of At-4/1-GFP expressed in epidermal cells of A. thaliana and N. benthamiana plants under higher magnification of CLSM revealed that the peripheral fluorescent punc-
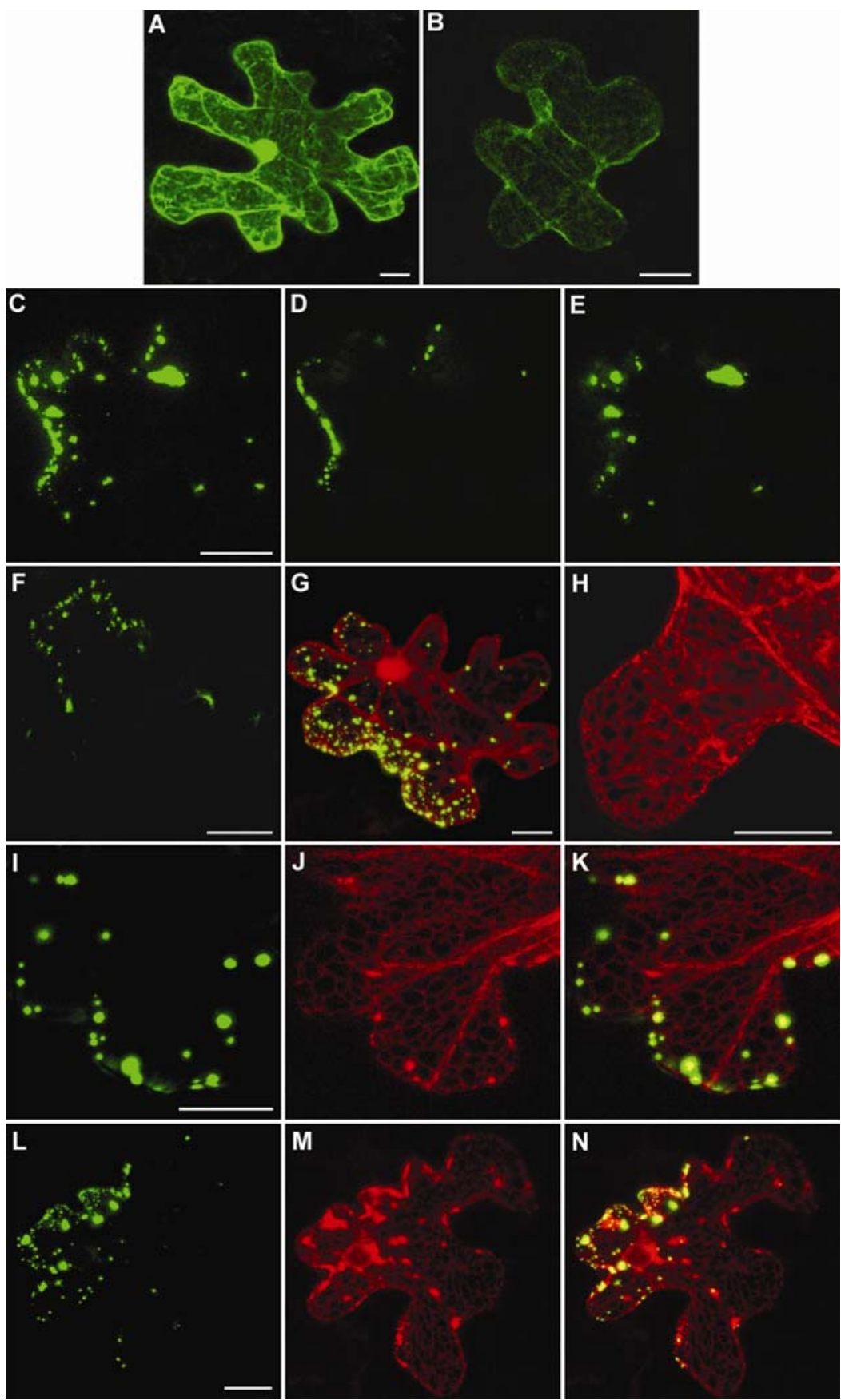

Fig. 3. Subcellular localization of the green fluorescent protein (GFP)-fused At-4/1 protein in epidermal cells of Nicotiana benthamiana and Arabidopsis thaliana leaves. Cells transiently expressing the fusion protein after microprojectile bombardment were imaged by confocal laser scanning microscopy. A, Localization of GFP. B, Localization of GFP-At-4/1. C, Localization of At-4/1-GFP. Optical sections in D, a median layer and E, the upper cell surface of the cell shown in C. F, Localization of At-4/1-GFP in an A. thaliana cell. G, Polar distribution of At-4/1-GFP in a cell visualized by coexpression with DsRed. H, Localization of endoplasmic reticulum yellow fluorescent protein (ER-YFP); the fluorescent signal was digitally pseudocolored with red. I through N, Coexpression of At-4/1-GFP with ER-YFP. I through K, At-4/1-GFP-specific structures contain the ER marker. L through N, Reorganization of the ER in cells expressing At-4/1-GFP. The localization of At-4/1-GFP is shown in I and L. The YFP signal (J and M) was pseudocolored digitally with red to facilitate interpretation of merged images ( $\mathrm{K}$ and $\mathrm{N}$ ). Image $\mathrm{F}$ shows an $A$. thaliana cell; other images were derived from $N$. benthamiana cells. Except $\mathrm{D}$ and E, images represent projections of serial optical sections. Scale bars $=20 \mu \mathrm{m}$. 
tae located at the cellular periphery in many cases appeared as twin structures consisting of two disconnected bodies (Fig. 4A to C). Superposition of confocal and bright field images clearly showed that twin bodies were located on opposite sides of the cell walls separating leaf epidermal cells (Fig. 4C). It should be noted, however, that, in different epidermal cells, the ratio between the total number of visible peripheral punctae and twin structures varied greatly.

The basis for twin-body formation could be provided by the PD structures assuming an association of At-4/1 containing bodies at opposite neck regions of a particular PD or within the same pit field (Blackman and Overall 2001; Cowan et al. 2002; Erhardt et al. 2000; Lawrence and Jackson 2001). In contrast, the TMV and Cucumber mosaic virus (CMV) MPs were shown to be localized inside PD (Blackman et al. 1998; Oparka et al. 1997; Roberts and Oparka 2003).

To provide further evidence that the appearance of twin structures in the bombardment experiments reflected an intrinsic property of At-4/1 to move from cell to cell but was not a consequence of a cell stress caused by the experimental procedure, agroinoculation of $N$. tabacum leaves was performed at low and high dilutions of a bacterial culture. Almost all cell borders in the leaf areas infiltrated at high bacterial concentrations and expressing At-4/1-GFP in numerous neighboring cells showed fluorescent twin structures positioned at the cellular periphery (Fig. 4D). Importantly, single cells transformed at low bacterial concentrations also showed twin structures, confirming the cell-to-cell trafficking properties of At-4/1-GFP protein (Fig. 4E).

\section{Colocalization of At-4/1-containing structures with viral TGBp3 movement protein.}

Unfortunately, we were unable to compare subcellular localization of At-4/1-GFP and a fluorescent fusion of TSWV MP because both N- and C-terminal fusions of GFP (or YFP) to this protein gave no fluorescent signal or a very faint diffused signal (data not shown). Therefore, to analyze the possible relation of At-4/1 localization sites to viral MP translocation pathways, we used PSLV TGBp3 as a marker. The regular distribution of fluorescent twin bodies in transgenic plants expressing GFP-TGBp3 suggested that this virus MP might be incorporated into membrane compartments near the PD orifice (Lucas and Lee 2004; Morozov and Solovyev 2003; Oparka
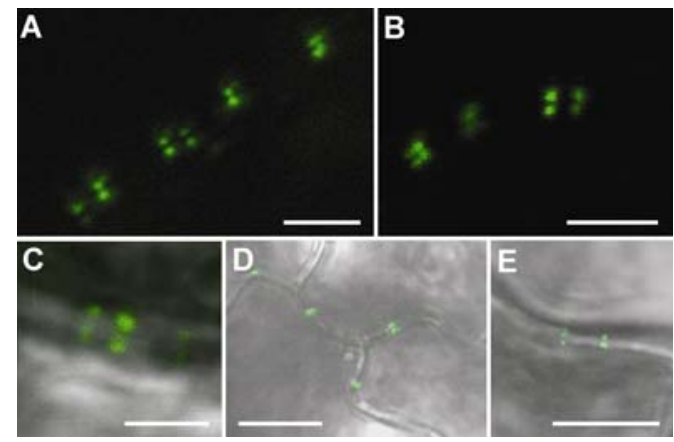

Fig. 4. Intercellular transport of At-4/1 protein. Twin structures at the cell borders of A, Arabidopsis thaliana and $\mathbf{B}$ and $\mathbf{C}$, Nicotiana benthamiana epidermal cells expressing At-4/1-green fluorescent protein (GFP) after microprojectile bombardment. Panel $\mathrm{C}$ represents a superposition of GFP signal with the bright field image, demonstrating alignment of At-4/1-containing structures with cell wall. Cell-wall-associated At-4/1-containing twin-structures in $N$. tabacum cells expressing the fusion protein At-4/1GFP D, after agroinfiltration at high density of bacterial suspension to enable protein expression in multiple neighboring cells and $\mathbf{E}$, at low concentration of bacteria to observe isolated transformed cells. Scale bars $=4$ $\mu \mathrm{m}$ in $\mathrm{A}$ and $\mathrm{B}, 2 \mu \mathrm{m}$ in $\mathrm{C}$, and $10 \mu \mathrm{m}$ in $\mathrm{D}$ and $\mathrm{E}$.
2004). Previous data on colocalization of callose deposits and GFP-TGBp3 strongly supported this hypothesis (Gorshkova et al. 2003). Fluorescent microscopy of At-4/1-GFP also suggested its association with cell walls and specified membranes (particularly the ER) (Fig. 3I to N), apparently identical with or at least similar to the subcellular location of the PSLV TGBp3 MP (Gorshkova et al. 2003). To gain insight into the origin of 4/1-specific peripheral punctate bodies and their possible relationship to PD, we cobombarded A. thaliana and $N$. benthamiana leaves with vectors expressing At-4/1-GFP and PSLV YFP-TGBp3 fusions. Subsequent dual color imaging of GFP and YFP in the transfected epidermal cells revealed colocalizations and close associations of both proteins near the cell walls (Fig. 5A to C). These pictures indicated that At-4/1 and TGBp3 are targeted to a similar or the same subcellular compartment. Interestingly, CLSM at high magnification revealed that At-4/1 fluorescent signals inside the TGBp3-specific peripheral bodies were distributed as groups of small granular bodies and not diffusely dispersed as the TGBp3 fluorescent signal (Fig. 5D to F).

To verify colocalization of At-4/1 and PSLV TGBp3 and their possible association with PD, we performed immunogold labeling experiments. A. thaliana leaf tissue was subjected to plasmolysis, and subsequently leaf extracts were processed for electron microscopy according to Bayer and associates (2004). Using At-4/1-specific antibodies, specific gold labeling was observed in membranous sacks (large vesicular structures) but not in PD-related structures described by Bayer and associates (2004) (Fig. 5G).

In similarly processed samples of $N$. benthamiana leaves prepared $40 \mathrm{~h}$ post inoculation with GFP-TGBp3-expressing agrobacteria, double labeling with gold particles of different diameters indicated that a protein from $N$. benthamiana immunologically related to At-4/1 and PSLV-TGBp3 solely colocalized in membranous sacks (Fig. 5I). Importantly, the labeling of other structures visible in cell extracts was negligible for both At-4/1 and PSLV-TGBp3 (Fig. 5H; data not shown). Thus, our experiments utilizing fluorescent and immunoelectron microscopy clearly demonstrated that both At-4/1 and PSLV-TGBp3 are incorporated into membrane bodies in the vicinity of PD but are not embedded in cell walls, namely, within the PD.

\section{DISCUSSION}

Cell-to-cell communication is a crucial prerequisite for the development and maintenance of multicellular organisms. Investigation of this mechanism in plants is of general biological significance because an understanding of such communication will be the basis to study the functional integrity in cell ensembles comprising multicellular organisms (Heinlein and Epel 2004; Waigmann et al. 2004). Although recent findings have significantly developed our understanding of macromolecular trafficking through PD as it is mediated by specialized cellular and viral proteins, the intrinsic workings of this process have not yet been revealed (Cilia and Jackson 2004; Gallagher and Benfey 2005; Heinlein and Epel 2004; Kim 2005; Lucas and Lee 2004; Nelson 2005; Oparka 2004; Ruiz-Medrano et al. 2004; Scholthof 2005; Ueki and Citovsky 2005; Waigmann et al. 2004).

For many years, A. thaliana has been used as a model plant to elucidate the molecular mechanisms of different biological processes. A number of recent studies have identified several A. thaliana genes involved in the intercellular movement of macromolecules (Faulkner et al. 2005; Kellmann 2001; Kim et al. 2003; Waigmann et al. 2004). We analyzed the At-4/1 protein from A. thaliana, which has been shown to be capable of 
interacting with a plant virus MP (von Bargen et al. 2001), with respect to its subcellular location and trafficking properties. At-4/1 localization was studied by particle bombardment of $N$. benthamiana and A. thaliana leaves as well as agroinfiltration of $N$. tabacum leaves using constitutive expression from recombinant At-4/1 gene constructs. In all experimental approaches with the different plant species examined, the location of At-4/1-GFP was similar (i.e., displaying small periph- eral bodies [punctae and twin bodies] at the cellular periphery) (Figs. 3 and 4).

Peripheral punctae also have been observed in experiments using GFP-tagged cellular proteins (Fridborg et al. 2003; Huang et al. 2001; Kim et al. 2002, 2003) as well as several plant virus MPs (Canto and Palukaitis 2005; Cowan et al. 2002; Epel et al. 1996; Itaya et al. 1998; Ju et al. 2005; Morozov and Solovyev 2003; Roberts and Oparka 2003; Solovyev et al.
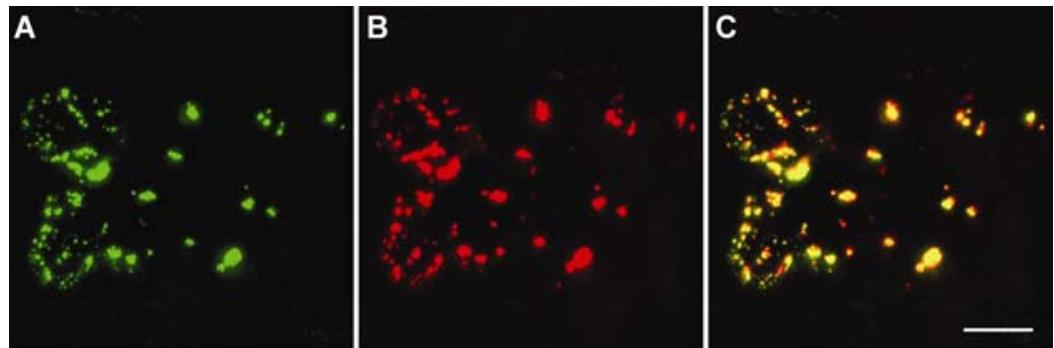

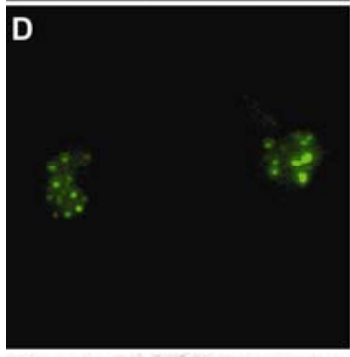

E
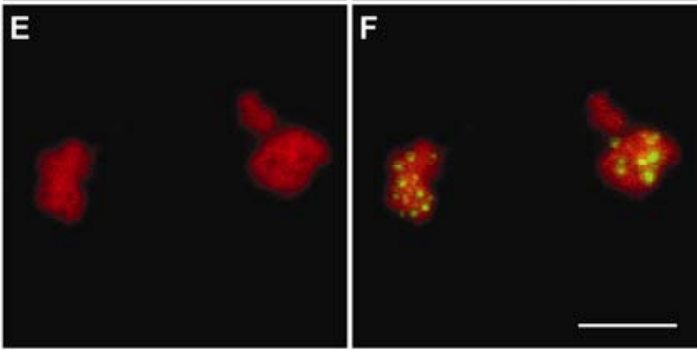

G

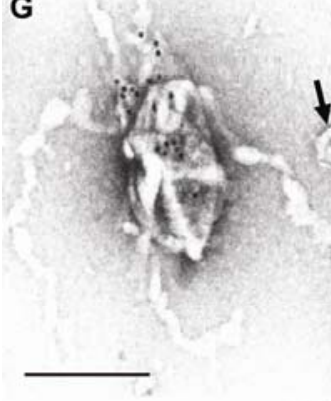

H

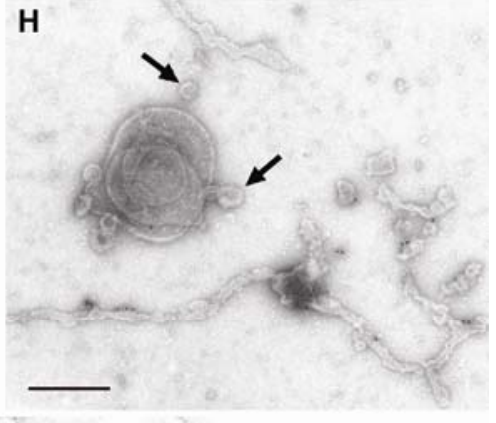

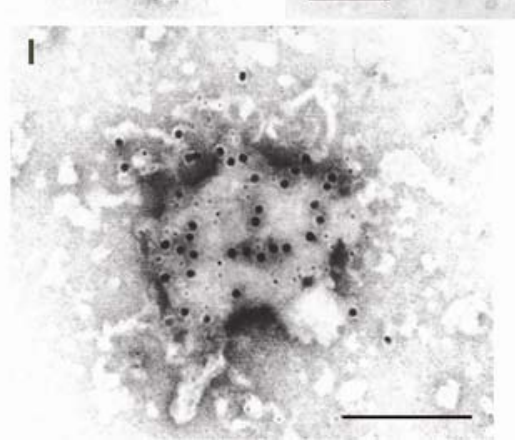

Fig. 5. Colocalization of At-4/1 protein with the viral movement protein TGBp3. A through F, Confocal laser scanning images of Nicotiana benthamiana cells coexpressing At-4/1-green fluorescent protein (GFP) with yellow fluorescent protein (YFP)-fused Poa semilatent virus (PSLV)-TGBp3 after microprojectile bombardment. Images show $\mathbf{A}$ through $\mathbf{C}$, colocalization of the two proteins and $\mathbf{D}$ through $\mathbf{F}$, association of At-4/1-containing granules with TGBp3-specific bodies, visible with higher magnification. A and D, Localization of At-4/1-GFP. The YFP signal (B and E) was pseudocolored digitally with red to facilitate interpretation of merged images (C and F). G, Immunogold labeling with rabbit anti-At-4/1 antibodies and secondary goat anti-rabbit antibodies conjugated with 20-nm gold particles. Electron microscopy of At-4/1 protein in samples prepared according to Bayer and associates (2004) from Arabidopsis thaliana leaves shows association of the protein with vesicular membrane structures. $\mathbf{H}$, Control labeling of $A$. thaliana leaf samples with preimmune serum. In experiments with anti-At-4/1 antibodies, and for each vesicular membrane structure containing immunogold labeling, the number of gold particles was counted and the membrane structure area was measured. Based on these data, the number of gold particles was found to be $712 \pm 91$ particles $/ \mu \mathrm{m}^{2}$ as calculated from $25 \mathrm{At}-4 / 1$ antibody-labeled membrane structures. In the control, when a preimmune serum was used, the number of gold particles was found to be $5.8 \pm 2.9$ particles $/ \mu \mathrm{m}^{2}$ as calculated from 25 membrane structures. The numbers of gold particles found outside membrane structures in samples treated with anti-At-4/1 antibodies and preimmune serum, calculated from 25 examined fields, were $4.9 \pm 2.6$ and $5.1 \pm 2.7$ particles $/ \mu \mathrm{m}^{2}$, respectively. I, Immunogold labeling and electron microscopy of At-4/1 protein and TGBp3 protein in samples from N. benthamiana leaves infiltrated with an agrobacterial culture harboring an expression plasmid with the GFP-TGBp3 gene. At-4/1 was detected with rabbit anti-At-4/1 antibodies and secondary goat anti-rabbit antibodies conjugated with 20-nm gold particles. GFP-fused TGBp3 was detected with anti-GFP monoclonal antibodies and secondary goat anti-mouse antibodies conjugated with 10 -nm gold particles. Arrows in $\mathrm{G}$ and $\mathrm{H}$ point to plasmodesmata typically present in samples prepared by the method used (Bayer et al. 2004). Scale bars $=20 \mu \mathrm{m}(\mathrm{C}), 4 \mu \mathrm{m}(\mathrm{F}), 0.2 \mu \mathrm{m}$ (G and H), and $0.1 \mu \mathrm{m}$ (I). 
2000; Tremblay et al. 2005; D. Ehrhardt and M. Pott, personal communication). The exact nature of the cellular, cortical compartment in which At-4/1-GFP accumulation has been observed is still unclear. In our studies, the At-4/1 protein was not present inside the cell-wall like the TMV and CMV MPs (Blackman et al. 1998; Epel et al. 1996; Itaya et al. 1998; Oparka et al. 1997; Roberts and Oparka 2003), but, rather, was located in the cellwall-adjoining cytoplasm, most probably in membrane bodies connected to the cortical ER (Figs. 3 and 4), as in the case of the plant cell-specific non-cell autonomous pathway protein 1 (NCAPP1) (Lee et al. 2003). Similar localizations have been shown for TGB-specific MPs (Gorshkova et al. 2003; Morozov and Solovyev 2003; Zamyatnin et al. 2004). Tight membrane association of At-4/1 also was confirmed by biochemical fractionation studies. The protein was localized mostly to the cell wall pellet fraction and solubilized upon Triton X-100 or (partially) Tween 20 treatment (our unpublished data).

In previous experiments using transgenic $N$. benthamiana plants constitutively expressing the PSLV TGBp3 protein fused to GFP, Gorshkova and associates (2003) found that this protein had a tendency to form peripheral bodies appearing as pairs of opposing discrete structures (twin bodies). Importantly, callose staining also showed the paired spots around the centre of the PD pore (Oparka et al. 1997). Thus, colocalization of TGBp3 twin spots with callose (Gorshkova et al. 2003) strongly indicates a close association with PD. Because the appearance of the twin-structured bodies formed by the PSLV TGBp3-MP resembled the appearance we observed of the cellular localization of At-4/1 (Fig. 3), we were prompted to coexpress At-4/1 together with PSLV TGBp3. Subsequent CLSM indicated that At-4/1 and TGBp3 are targeted to a similar or the same subcellular compartment (Fig. 5). However, At-4/1 fluorescent signals inside TGBp3-decorated peripheral fluorescent bodies appeared in groups of small granular bodies, suggesting membranous substructures within the TGBp3-targeted vesicles to which At-4/1 is attached.

A special feature of the subcellular At-4/1-GFP localization pattern is the polarized distribution of peripheral fluorescent punctae in epidermal cells and the ability to move cell-to-cell in leaves of $A$. thaliana and $N$. benthamiana. Obviously, only one-half of an epidermal cell contains fluorescent punctae or shows cell-to-cell movement of At-4/1 (Fig. 3G). This phenotype strongly corroborates that the GFP-fused At-4/1 protein retained its ability for specific subcellular trafficking. Therefore, we presume that the observed structures where At-4/1 was found to be localized represent the compartment of native protein location rather than being a result of aggregation of overaccumulated protein.

In the case of plant phototropin 1 , it also was found that the protein is localized in polar fashion at the plasma membrane regions adjacent to apical and basal cell end walls in the elongating stem (Sakamoto and Briggs 2002). Polar distribution to the youngest cell walls was found for MP of Grapevine fanleaf virus (GFLV) in tobacco cell suspension culture (Laporte et al. 2003). Plant cell expansion, which controls cell shape and size, also is accomplished by polarized protein trafficking (Falbel et al. 2003; Fu et al. 2002; Jones et al. 2002; Kang et al. 2003; Zuo et al. 2000). Thus, it can be speculated that 4/1-like proteins somehow are involved in secondary cell expansion.

Biochemical analyses utilizing both in vitro methods, such as immunoprecipitation, or in vivo assays, such as yeast twohybrid system, can confirm MP-host protein interactions and even specificity; however, in many cases, their functionality and biological role during cell-to-cell trafficking of viruses or virus-derived macromolecules remained only partially understood. For example, pectin methylesterase and calreticulin were found not only to interact with the TMV-encoded MP but also positively influenced virus spreading (Chen and Citovsky 2003; Chen et al. 2005). In contrast, binding of TMV MP to the microtubule-associated protein MPB2C interfered with TMV cell-to-cell movement (Kragler et al. 2003). Considering these insights, the $4 / 1$ protein may assist virus movement through PD or, in contrast, the TSWV MP may remove the 4/1 protein from PD-associated compartments to mediate spreading of the virus. Interestingly, constitutive expression of TSWV MP in transgenic plants results in sealing of PD and pronounced deficiencies in root and shoot development (Rinne et al. 2005; M. Paape and J.-W. Kellmann, unpublished). It can be speculated that these defects are due to removing 4/1 protein from a pool of functional molecules by excessive production of MP.

In addition to our previously published data showing that At-4/1 specifically interacts with the TSWV MP using a yeast two-hybrid system (von Bargen et al. 2001), we here point out the colocalization of GFP-tagged At-4/1 protein with YFPlabeled TGBp3 MP encoded by PSLV. It is well accepted that the movement mechanisms of TSWV and PSLV (and related viruses) are quite different. Tospoviruses induce tubular structures at PDs, whereas PSLV, like Potexviruses, facilitates movement by expressing three different proteins from triple gene block cistrons (Carrington et al. 1996; Lucas 2006; VerchotLubicz 2005). This opens the question of whether At- $4 / 1$ is a common host factor interacting with different plant virus transport systems or, vice versa, represents one component of the plasmodesmal transport machinery which is required to successfully assemble or even move Tospovirus-induced tubules from cell to cell (Scholthof 2005).

To conclude, in this study, we have shown that 4/1-like proteins form a new family of plant proteins encoded by singlecopy genes, which presumably is present in all vascular plants. Due to their ability to move between plant cells, 4/1-polypeptides may provide an excellent target for studying intracellular protein trafficking and intercellular communication through PD.

\section{MATERIALS AND METHODS}

\section{Database search.}

Multiple database searches were performed to identify members of the family of 4/1-related proteins. We used the Basic Local Alignment Search Tool (BLAST) capabilities (TBLASTN and BLASTP) available on the National Center of Biotechnology Information databases. Intron-containing genomic nucleotide sequences were processed using the NetGene2 software to predict intron/exon boundaries in putative 4/1-like genes. Coiled-coil and leucine zipper region prediction was done according to the Multicoil program.

\section{Construction of recombinant clones.}

All recombinant DNA procedures were carried out by standard methods using Escherichia coli DH5- $\alpha$ and plasmids pRT-GFP, pRT-YFP-ER (containing the N-terminal signal sequence of $A$. thaliana basic chitinase and C-terminal ER-retention signal) (Boevink et al. 1998, 1999), and pRT-YFP-TGBp3 bearing the triple gene block $18 \mathrm{~K}$ movement protein of PSLV (genus Hordeivirus). These plasmids are 35S-promoter-based vectors originally prepared for transient expression assays in plants (Solovyev et al. 2000; Töpfer et al. 1987; Zamyatnin et al. 2002).

To obtain plasmid pGY1-At-4/1-GFP, we used the pGY1GFP plasmid (provided by Patrick Schweizer, IPK Gatersleben). Plasmid pGY1-GFP was digested with $B g l I I$ and subsequently partially digested with $N c o$ I. Large DNA fragments to be used for the insertion of the At-4/1 cDNA were obtained by gel ex- 
traction. The partial cDNA sequence of the original At-4/1 was completed using oligonucleotides referring to the full-length mRNA sequence of the corresponding gene (GenBank accession number NM_118735), with subsequent cloning using pGEMT vector. Afterward, At-4/1 complete coding sequence was polymerase chain reaction (PCR) amplified using $\mathrm{N}$-terminal $B g l \mathrm{II}$ and C-terminal NcoI primers with pGEMT-4/1 as a template. The resulting PCR fragments were cleaved with the respective enzymes and cloned into the similarly digested pGY1-GFP vector, leading to an in-frame fusion of At-4/1 to the N-terminus of GFP. All clones subsequently were scrutinized by sequencing. For 5' RACE, a kit for RNA ligase-mediated rapid amplification of cDNA ends (RLM-RACE) was used according to the instructions of the manufacturer (Ambion, Huntingdon, U.K.) with two nested primers complementary to At-4/1 mRNA, approximately 150 nucleotides downstream of the predicted translation initiator codon.

\section{Protein expression in plant cells.}

Particle bombardment of $N$. benthamiana and A. thaliana (Col-0) leaves was performed using the flying disc method (Daniell 1993) with a high-pressure helium-based PDS-1000 system (Bio-Rad, Hercules, CA, U.S.A.). For each series of shots, DNA $(1 \mu \mathrm{g})$ was precipitated on $30 \mathrm{mg}$ of tungsten particles $(\mathrm{M} 17,1.1 \mu \mathrm{m})$ by adding ice-cold calcium chloride $(0.7$ $M$ final concentration [f.c.]) and spermidine (10\% f.c.). After incubation for $10 \mathrm{~min}$ on ice and successive washing in 25 and $75 \%$ ethanol, the particles were resuspended by full-power sonification in $6.5 \mu \mathrm{l}$ of undiluted ethanol, and $5 \mu \mathrm{l}$ immediately were loaded on a plastic flying disk. The disk was used for bombardment after the particles were dried in a desiccator. Plants for bombardment were grown in a greenhouse in soil $\left(25^{\circ} \mathrm{C}\right.$, daylight of 10 to $\left.12 \mathrm{~h}\right)$. The largest fully expanded leaves were detached from 6-week-old plants, placed in the center of a plastic petri dish, and bombarded on a solid support at a target distance of $7 \mathrm{~cm}$ and a helium gas pulse of $1,550 \mathrm{psi}$ $(10,700 \mathrm{kPa})$.

\section{Agroinoculation.}

Agroinfiltration was carried out essentially as described by Yelina and associates (2005). Agrobacterium tumefaciens GV2260/C58C1, which carried the pLH7000-based binary vector harboring At-4/1-GFP fusion gene in an expression cassette, was cultured overnight at $28^{\circ} \mathrm{C}$ with $10 \mathrm{mM}$ MES and 20 $\mathrm{mM}$ acetosyringone, then resuspended in $10 \mathrm{mM}$ MES $(\mathrm{pH}$ 5.5), $10 \mathrm{mM} \mathrm{MgCl}$, and $150 \mathrm{mM}$ acetosyringone to a final density of optical density at $600 \mathrm{~nm}=1$, incubated for $3 \mathrm{~h}$ at room temperature, and infiltrated into $N$. benthamiana leaves. To observe isolated transformed cells, the bacterial suspension was diluted 1:1000 with $10 \mathrm{mM}$ MES (pH 5.5), $10 \mathrm{mM}$ $\mathrm{MgCl}_{2}$, and $150 \mathrm{mM}$ acetosyringone.

\section{Fluorescent microscopy.}

Fluorescence was detected using a Zeiss Axioscope 20 fluorescence microscope. For GFP detection, excitation filter BP450-490, beam splitter FT510, and emission filter HQ535/50x were used. Cells expressing GFP constructs were imaged on a Leica TCS SP2 CLSM system using an argon ion laser of $488 \mathrm{~nm}$ for GFP excitation. For imaging coexpressed YFP and GFP constructs with a TCS SP2 system, excitation lines of an argon ion laser of $488 \mathrm{~nm}$ for GFP and $514 \mathrm{~nm}$ for YFP were used alternately. Accordingly, fluorescence of GFP and YFP was detected alternately using the "switching between lines" option of the confocal system in a 496- to 510-nm acquisition window for GFP and 560- to 615-nm window for YFP. In this way, any bleeding of fluorescence between channels was eliminated (Brandizzi et al. 2002b). Projection of se- rial optical sections was performed using TCS SP2 software (Leica Microsystems, Wetzlar, Germany).

\section{Polyclonal antibodies.}

To obtain polyclonal antibodies against At-4/1 region, rabbits were immunized with an E. coli-expressed At-4/1 C-terminal fragment (amino acids 58 to 247). One rabbit was immunized three times at 2-week intervals with a His-tagged At-4/1 protein. For the first immunization, $560 \mu \mathrm{g}$ of protein in water was mixed with an equal volume of Freund's complete adjuvant and injected subcutaneously in a few points near the vertebral column. The second and third immunizations were done similarly, using an antigen mixed with Freund's incomplete adjuvant. One week after the final injection, blood from ear vein was taken for antiserum preparations. The immunoglobulin $\mathrm{G}$ (IgG) fraction from anti-At-4/1 rabbit antiserum was purified on a protein-G affinity column after ammonium sulfate precipitation. Mice were immunized intraperitoneally three times at 2 -week intervals, 50 to $70 \mu \mathrm{g}$ of antigen per mouse. Tail bleeding occurred 1 week after the final immunization. The $\mathrm{IgG}$ fraction was purified the same way as the rabbit IgG.

\section{Immunogold labeling.}

Plant tissue (150-200 mg) was cut into small pieces and incubated for 10 min with $1 \mathrm{ml}$ of buffer A (100 mM Tris $\mathrm{HCl}, \mathrm{pH}$ $8.0,100 \mathrm{mM} \mathrm{KCl}, 10 \mathrm{mM}$ EDTA, $10 \%$ glycerol, $0.45 \mathrm{M}$ mannitol), and a protease inhibitor cocktail for plant cells and tissue extracts at $10 \mu \mathrm{l} / \mathrm{ml}$ (Sigma, St. Louis). Afterward, samples were ground and centrifuged at $400 \times g$ for 5 min with cooling. The sediment was resuspended in buffer B $(100 \mathrm{mM}$ Tris $\mathrm{HCl}, \mathrm{pH}$ 8.0, $10 \mathrm{mM} \mathrm{KCl}, 10 \mathrm{mM}$ EDTA, $10 \%$ glycerol) and centrifuged twice at $400 \times g$ for $5 \mathrm{~min}$. Before the last centrifugation, protein inhibitor cocktail was added.

For immunogold labeling, 2- to 3- $\mu$ l aliquots of supernatant were pipetted onto Formvar-carbon-coated grids and subsequently air dried. The samples were preblocked by incubation for $15 \mathrm{~min}$ in $0.1 \mathrm{M}$ sodium cacodylate buffer, $1 \%$ bovine serum albumin, pH 7.4 (CB), then washed with $\mathrm{CB}$ and incubated overnight at room temperature with polyclonal mouse or rabbit anti-At-4/1 antibodies ( 2 to $5 \mu \mathrm{g} / \mathrm{ml}$ ), or a mouse monoclonal anti-GFP antibody $(10 \mu \mathrm{g} / \mathrm{ml})$. After washing, the grids were incubated for $2 \mathrm{~h}$ at room temperature with goat anti-mouse or anti-rabbit $\operatorname{IgG}$, conjugated beforehand to 5,10 , or $15 \mathrm{~nm}$ of gold beads (Biocell, Cardiff, U.K.), and washed with distilled water. Finally, grids were stained with $2 \%$ uranyl acetate and air dried.

\section{ACKNOWLEDGMENTS}

This work was supported in part by the Ministerium für Kultur und Wissenschaft, Forschungsschwerpunkt 'Agrarbiotechnologie,' Lower Saxony (Grant Zn603); by the Volkswagen-Stiftung, Federal Republic of Germany; by a Ph.D. scholarship to M. Paape (Graduiertenfoerderung of Mecklenburg-Western Pomerania); by grants of the Deutsche Forschungsgemeinschaft to J.-W. Kellmann (KE 690/1 and 690/4); by the Russian Foundation for Basic Research (RFBR) grants 04-04-49126 and 06-0449129; and by the German-Russian Inter-Governmental Program for Cooperation in Agricultural Sciences. Many thanks to C. Bauer for skillful technical assistance, S. von Bargen for substantial discussion, E. Wheeler for editorial work, and G. Langen, University of Giessen, for preliminary and promising CLSM experiments.

\section{LITERATURE CITED}

Bayer, E., Thomas, C. L., and Maule, A. J. 2004. Plasmodesmata in Arabidopsis thaliana suspension cells. Protoplasma 223:93-102.

Blackman, L. M., and Overall, R. L. 2001. Structure and function of plasmodesmata. Aust. J. Plant. Physiol. 28:709-727.

Blackman, L. M., Boevink, P., Santa Cruz, S., Palukaitis, P., and Oparka, K. 1998. The movement protein of cucumber mosaic virus traffics into 
sieve elements in minor veins of Nicotiana clevelandii. Plant Cell 10:525-537.

Boevink, P., Oparka, K., Sant Cruz, S., Martin, B., Betteridge, A., and Hawes, C. 1998. Stacks on tracks: The plant Golgi apparatus traffics on an actin/ER network. Plant J. 15:441-447.

Boevink, P., Martin, B., Oparka, K., Santa Cruz, S., and Hawes, C. 1999. Transport of virally expressed green fluorescent protein through the secretory pathway in tobacco leaves is inhibited by cold shock and brefeldin A. Planta 208:392-400.

Brandizzi, F., Fricker, M., and Hawes, C. 2002a. A greener world: The revolution in plant bioimaging. Nat. Rev. Mol. Cell Biol. 3:520-530.

Brandizzi, F., Snapp, E. L., Roberts, A. G., Lippincott-Schwartz, J., and Hawes, C. 2002b. Membrane protein transport between the endoplasmic reticulum and the golgi in tobacco leaves is energy dependent but cytoskeleton independent: evidence from selective photobleaching. Plant Cell 14:1293-1309.

Canto, T., and Palukaitis, P. 2005. Subcellular distribution of mutan movement proteins of Cucumber mosaic virus fused to green fluorescent proteins. J. Gen. Virol. 86:1223-1228.

Carrington, J. C., Kasschau, K. D., Mahajan, S. K., and Schaad, M. C. 1996. Cell-to-cell and long-distance transport of viruses in plants. Plant Cell 8:1669-1681.

Chen, M. H., and Citovsky, V. 2003. Systemic movement of a Tobamovirus requires host cell pectin methylesterase. Plant J. 35:386-392.

Chen, M. H., Tian, G.-W., Gafni, Y., and Citovsky, V. 2005. Effects of calreticulin on viral cell-to-cell movement. Plant Physiol. 138:1866-1876.

Cilia, M. L., and Jackson, D. 2004. Plasmodesmata form and function. Curr. Opin. Cell Biol. 16:500-506.

Citovsky, V., Wong, M. L., Shaw, A. L., Prasad, B. V., and Zambryski, P. 1992. Visualization and characterization of Tobacco mosaic virus movement protein binding to single-stranded nucleic acids. Plant Cell 4:397411.

Cowan, G. H., Lioliopoulou, F., Ziegler, A., and Torrance L. 2002. Subcellular localisation, protein interactions, and RNA binding of Potato moptop virus triple gene block proteins. Virology 298:106-115.

Daniell, H. 1993. Foreign gene expression in chloroplasts of higher plants mediated by tungsten particle bombardment. Methods Enzymol. 217:536-556

Epel, B. L., Padgett, H. S., Heinlein, M., and Beachy, R. N. 1996. Plant virus movement protein dynamics probed with a GFP-protein fusion. Gene 173:75-79.

Erhardt, M., Morant, M., Ritzenthaler, C., Stussi-Garaud, C., Guilley, H., Richards, K. E., Jonard, G., Bouzoubaa, S., and Gilmer, D. 2000. P42 movement protein of Beet necrotic yellow vein virus is targeted by the movement proteins p13 and p15 to punctate bodies associated with plasmodesmata. Mol. Plant-Microbe Interact. 13:520-528.

Falbel, T. G., Koch, L. M., Nadeau, J. A., Segui-Simarro, J. M., Sack, F. D., and Bednarek, S. Y. 2003. SCD1 is required for cell cytokinesis and polarized cell expansion in Arabidopsis thaliana. Development 130:4011-4024.

Faulkner, C., Brandom, J., Maule, A., and Oparka, K. 2005. Plasmodesmata 2004. Surfing the Symplasm. Plant Physiol. 137:607-610.

Fridborg, I., Grainger, J., Page, A., Coleman, M., Findlay, K., and Angell, S. 2003. TIP, a novel host factor linking callose degradation with the cell-to-cell movement of Potato virus X. Mol. Plant-Microbe Interact. 16:132-140

Fu, K., Li, H., and Yang, Z. 2002. The ROP2 GTPase controls the formation of cortical fine F-actin and the early phase of directional cell expansion during Arabidopsis organogenesis. Plant Cell 14:777-794.

Gallagher, K. L., and Benfey, P. N. 2005. Not just another hole in the wall: Understanding intercellular protein trafficking. Genes Dev. 19:189-195.

Gorshkova, E. N., Erokhina, T. N., Stroganova, T. A., Yelina, N. E., Zamyatnin, A. A. Jr., Kalinina, N. O., Schiemann, J., Solovyev, A. G. and Morozov, S. Yu. 2003. Immunodetection and fluorescent microscopy of transgenically expressed Hordeivirus TGBp3 movement protein reveals its association with endoplasmic reticulum elements in close proximity to plasmodesmata. J. Gen. Virol. 84:985-994.

Haywood, V., Kragler, F., and Lucas, W. J. 2002. Plasmodesmata: Pathways for protein and ribonucleoprotein signaling. Plant Cell 14 (Suppl.):S303-S325.

Heinlein, M. 2002. Plasmodesmata: dynamic regulation and role in macromolecular cell-to-cell signaling. Curr. Opin. Plant Biol. 5:543-552.

Heinlein, M., and Epel, B. L. 2004. Macromolecular transport and signaling through plasmodesmata. Int. Rev. Cytol. 235:93-164.

Huang, Z., Andrianov, V. M., Han, Y., and Howell, S. H. 2001. Identification of Arabidopsis proteins that interact with the Cauliflower mosaic virus (CaMV) movement protein. Plant Mol. Biol. 47:663-675.

Itaya, A., Woo, Y.-M., Masuta, C., Bao, Y., Nelson, R. S., and Ding, B. 1998. Developmental regulation of intercellular protein trafficking through plasmodesmata in tobacco leaf epidermis. Plant Physiol.
118:373-385.

Jones, M. A., Shen, J.-J., Fu, Y., Li, H., Yang, Z., and Grierson, C.S. 2002. The Arabidopsis Rop2 GTPase is a positive regulator of both root hair initiation and tip growth. Plant Cell 14:763-776.

Ju, H.-J., Samuels, T. D., Wang, Y.-S., Blancaflor, E., Payton, M., Mitra, R., Krishnamurthy, K., Nelson, R. S., and Verchot-Lubicz, J. 2005. The Potato virus $X$ TGBp2 movement protein associates with endoplasmic reticulum-derived vesicles during virus infection. Plant Physiol. 138:1877-1895.

Kang, B.-H., Busse, J. S., and Bednarek, S.Y. 2003. Members of the Arabidopsis dynamin-like genes family, ADL1, are essential for plant cytokinesis and polarized cell growth. Plant Cell 15:899-913.

Kellmann, J.-W. 2001. Identification of plant virus movement-host protein interactions. Z. Naturforsch. 56:669-679.

Kim, J.-Y. 2005. Regulation of short-distance transport of RNA and protein. Curr. Opin. Plant Biol. 8:45-52.

Kim, J.-Y., Yuan, Z., Cilia, M., Khalfan-Jagani, Z., and Jackson, D. 2002. Intercellular trafficking of a KNOTTED1 green fluorescent protein fusion in the leaf and shoot meristem of Arabidopsis. Proc. Nat. Acad. Sci. U.S.A. 99:4103-4108.

Kim, J.-Y., Yuan, Z., and Jackson, D. 2003. Developmental regulation and significance of KNOX protein trafficking in Arabidopsis. Development 130:4351-4362

Kiselyova, O. I., Yaminsky, I. V., Karger, E. M., Frolova, O. Yu., Dorokhov, Y. L., and Atabekov, J. G. 2001. Visualization by atomic force microscopy of Tobacco mosaic virus movement protein-RNA complexes formed in vitro. J. Gen. Virol. 82:1503-1508.

Kragler, F., Lucas, W. J., and Monzer, J. 1998. Plasmodesmata: dynamics, domains and patterning. Ann. Bot. 81:1-10.

Kragler, F., Curin, M., Trutnyeva, K., Gansch, A., and Waigmann E. 2003. MPB2C, a microtubule-associated plant protein, binds to and interferes with cell-to-cell transport of Tobacco mosaic virus movement protein. Plant Physiol. 132:1870-1883.

Laporte, C., Vetter, G., Loudes, A.-M., Robinson, D. G., Hillmer, S., Stussi-Garaud, C., and Ritzenthaler, C. 2003. Involvement of the secretory pathway and the cytoskeleton in intracellular targeting and tubule assembly of Grapevine fanleaf virus movement protein in tobacco BY-2 cells. Plant Cell 15:2058-2075.

Lawrence, D. M., and Jackson, A. O. 2001. Interactions of the TGB1 protein during cell-to-cell movement of Barley stripe mosaic virus. J. Virol. 75:8712-8723.

Lazarowitz, S. G., and Beachy, R. N. 1999. Viral movement proteins as probes for intracellular and intercellular trafficking in plants. Plant Cell 11:535-548.

Lee, J.-Y., Yoo, B.-C., Rojas, M. R., Gomez-Ospina, N., Staehelin, L. A., and Lucas, W. J. 2003. Selective trafficking of non-cell-autonomous proteins mediated by NtNCAPP1. Science 299:392-396.

Lucas, W. J. 2006. Plant viral movement proteins: agents for cell-to-cell trafficking of viral genomes. Virology 344:169-184.

Lucas, W. J., and Lee, J.-Y. 2004. Plasmodesmata as a supracellular control network in plants. Nat. Rev. Mol. Cell Biol. 5:712-726.

Lupas, A. 1996. Coiled-coiles: New structures and new functions. Trends Biochem Sci. 21:375-382.

Lupas, A., Van Dyke, M., and Stock, J. 1991. Predicting coiled coils from protein sequences. Science 252:1162-1164.

Melcher, U. 2000. The ' $30 \mathrm{~K}$ ' superfamily of viral movement proteins. J. Gen. Virol. 81:257-266.

Morozov, S. Y., and Solovyev, A. G. 1999. Genome organization in RNA viruses. Pages 47-98 in: Molecular Biology of Plant Viruses. C. L. Mandahar, ed. Kluwer Academic Publishers, Dordrecht, The Netherlands.

Morozov, S. Yu., and Solovyev, A. G. 2003. Triple gene block: modular design of a multifunctional machine for plant virus movement J. Gen. Virol. 84:1351-1366.

Nelson, R. S. 2005. Movement of viruses to and through plasmodesmata. Pages 188-209 in: Plasmodesmata. K. Oparka, ed. Blackwell Publishing Ltd., Oxford, U.K.

Oparka, K. J. 2004. Getting the message across: How do plant cells exchange macromolecular complexes? Trends Plant Sci. 9:33-41.

Oparka, K. J., Prior, D. A. M., Santa Cruz, S., Padgett, H. S., and Beachy, R. N. 1997. Gating of epidermal plasmodesmata is restricted to the leading edge of expanding infection sites of tobacco mosaic virus (TMV). Plant J. 12:781-789.

Rinne, P. L. H., van den Boogaard, R., Mensink, M. G. J., Kopperud, C., Kormelink, R., Goldbach, R., and van der Schoot, C. 2005. Tobacco plants respond to the constitutive expression of the Tospovirus movement protein NSm with a heat-reversible sealing of plasmodesmata that impairs development. Plant J. 43:688-707.

Roberts, A. G., and Oparka, K. J. 2003. Plasmodesmata and the control of symplastic transport. Plant Cell Environ. 26:103-124.

Ruiz-Medrano, R., Xoconostle-Cazares, B., and Kragler, F. 2004. The 
plasmodesmatal transport pathway for homeotic proteins, silencing signals and viruses. Curr. Opin. Plant Biol. 7:641-650.

Sakamoto, K., and Briggs, W. R. 2002. Cellular and subcellular localization of phototropin 1. Plant Cell 14:1723-1735.

Schepetilnikov, M. V., Manske, U., Solovyev, A. G., Zamyatnin Jr., A. A., Schiemann, J., and Morozov, S. Yu. 2005. The hydrophobic segment of Potato virus $X$ TGBp3 is a major determinant of the protein intracellular trafficking. J. Gen. Virol. 86:2379-2391.

Scholthof, H. B. 2005. Plant virus transport: Motions of functional equivalence. Trends Plant Sci. 10:376-382.

Solovyev, A. G., Stroganova, T. A., Zamyatnin, A. A., Jr., Fedorkin, O. N., Schiemann, J., and Morozov, S. Yu. 2000. Subcellular sorting of small membrane-associated triple gene block proteins: TGBp3-assisted targeting of TGBp2. Virology 269:113-127.

Töpfer, R., Matzeit, V., Gronenborn, B., Schell, J., and Steinbiss, H.-H. 1987. A set of plant expression vectors for transcriptional and translational fusions. Nucleic Acids Res. 15:5890.

Tremblay, D., Vaewhongs, A. A., Turner, K. A., Sit, T. L., and Lommel, S. A. 2005. Cell wall localization of Red clover necrotic mosaic virus movement protein is required for cell-to-cell movement. Virology 333:10-21.

Tzfira, T., Rhee, Y., Chen, M. H., Kunik, T., and Citovsky, V. 2000. Nucleic acid transport in plant-microbe interactions: The molecules that walk through the walls. Annu. Rev. Microbiol. 54:187-219.

Ueki, S., and Citovsky, V. 2005. Control improves with age: Intercellular transport in plant embryos and adults. Proc. Natl. Acad. Sci. U.S.A. 102:1817-1818.

Verchot-Lubicz, J. 2005. A new cell-to-cell transport model for Potexviruses. Mol. Plant-Microbe Interact. 18:283-290.

von Bargen, S., Salchert, K., Paape, M., Piechulla, B., and Kellmann, J.-W 2001. Interactions between the Tomato spotted wilt virus movement protein and plant proteins showing homologies to myosin, kinesin and DnaJ-like chaperones. Plant Physiol. Biochem. 39:1083-1093.

Waigmann, E., Ueki, S., Trutnyeva, K., and Citovsky, V. 2004. The Ins and Outs of nondestructive cell-to-cell and systemic movement of plant viruses. Crit. Rev. Plant Sci. 23:195-250.

Yelina, N. E., Erokhina, T. N., Lukhovitskaya, N. I., Minina, E. A Schepetilnikov, M. V., Lesemann, D. E., Schiemann, J., Solovyev, A. G., and Morozov, S. Yu. 2005. Localization of Poa semilatent virus cysteine-rich protein in peroxisomes is dispensable for its ability to suppress RNA silencing. J. Gen. Virol. 86:479-489.

Zamyatnin, A. A., Jr., Solovyev, A. G., Sablina, A. A., Agranovsky, A. A Katul, L., Vetten, H. J., Schiemann, J., Hinkkanen, A. E., Lehto, K., and Morozov, S. Yu. 2002. Dual-color imaging of membrane protein targeting directed by poa semilatent virus movement protein TGBp3 in plant and mammalian cells. J. Gen. Virol. 83:651-662.

Zamyatnin, A. A., Jr., Solovyev, A. G., Savenkov, E. I., Germundsson, A., Sandgren, M., Valkonen, J. P. T., and Morozov, S. Yu. 2004. Transient coexpression of individual genes encoded by the triple gene block of Potato mop-top virus reveals requirements for TGBp1 trafficking. Mol. Plant-Microbe Interact. 17:921-930.

Zuo, J., Niu, Q., Nishizawa, N., Wu, Y., Kost, B., and Chua, N. 2000 KORRIGAN, an Arabidopsis endo-1,4- $\beta$-glucanase, localizes to the cell plate by polarized targeting and is essential for cytokinesis. Plant Cell 12:1137-1152.

\section{AUTHOR-RECOMMENDED INTERNET RESOURCES}

National Center of Biotechnology Information: www.ncbi.nlm.nih.gov NetGene2 software: www.cbs.dtu.dk/services/NetGene2

Multicoil program: multicoil.lcs.mit.edu/cgi-bin/multicoil 